TIAGO LUÍS SAURA

\title{
A CONCILIAÇÃO JUDICIAL - TEMPO, AFETOS E EXPLORAÇÃO
}

\author{
DISSERTAÇÃO DE MESTRADO \\ ORIENTADOR: Professor Doutor Flávio Roberto Batista.
}

UNIVERSIDADE DE SÃO PAULO

FACULDADE DE DIREITO

SÃO PAULO - SP

2018 


\section{A CONCILIAÇÃO JUDICIAL - TEMPO, AFETOS E EXPLORAÇÃO}

Dissertação apresentada à Banca Examinadora do Programa de PósGraduação em Direito, da Faculdade de Direito da Universidade de São Paulo, como exigência para obtenção do grau de Mestre em Direito do Trabalho e Seguridade Social, sob a orientação do Professor Doutor Flávio Roberto Batista.

FACULDADE DE DIREITO

SÃO PAULO - SP 
Ao meu avô Jundenyr Nicolau que realiza, de forma póstuma, o sonho de ver seu nome vinculado à Universidade. 
Primeiro devo agradecer aos meus pais pelo apoio ao longo dos anos, meu pai fonte inspiração na carreira docente, minha mãe fonte de inspiração no trato com a vida.

À Mariana, companheira de longos anos, amiga do banco de faculdade e parceira das lutas da advocacia, qual tenho a honra de dividir meus dias e o amor.

Ao meu irmão pelo companheirismo e por ser modelo de ética nas relações de trabalho.

Ao meu orientador Flávio Roberto Batista, que ao longo dos anos foi muito além da figura e atribuições de um orientador, foi amigo, companheiro de luta, parceiro pesquisador, um ombro amigo e norte para essa tarefa árdua de promover a crítica imanente.

Ao professor Marcus Orione Gonçalves Correia pela humildade e dedicação ao promover o conhecimento e buscar de forma feroz, algo que aprendi e não abandonarei jamais, a realidade dos livros, a profundidade das teorias.

Ao professor Jorge Luiz Souto Maior por me acolher no início de minha pesquisa e por dar um sentido para minhas inquietações.

Aos companheiros e às companheiras do Núcleo de estudos sobre teoria e prática da greve no direito sindical brasileiro contemporâneo que batalham de forma incansável pela pesquisa das condições e direitos da classe trabalhadora, assim enriquecem os entendimentos do que deve ser a greve, o Direito Coletivo do Trabalho e o Direito do Trabalho Individual.

Às companheiras de escritório Karen e Gabriella que exemplificam a nova geração dos advogados com garra para a luta por melhores condições para a população em geral. 
O presente trabalho busca a crítica imanente à figura da conciliação em processos individuais com pleito de pagamento de verbas salariais não pagas.

Para tanto utilizamos o tempo como linha mestre para a crítica. Passamos pelo tempo processual, pela expectativa do tempo e pelos afetos que envolvem o tempo e as relações sociais, como o medo, o desamparo e a esperança.

Estabelecemos qual a função do Estado na exploração da força de trabalho e manutenção do capitalismo, bem como a utilização do poder e dos afetos.

Ademais, apresentamos o tempo da rotação do capital e como a conciliação e a demora processual podem ser úteis para o ganho do capitalista.

Apresentamos a conciliação como ferramenta de exploração da classe trabalhadora e como há aceitação da conciliação com base nos afetos medo, esperança e desamparo.

PALAVRAS CHAVE: conciliação, tempo, exploração, pacificação, Estado, processo, mais-valor, medo, desamparo, esperança, política, precarização. 
The present work seeks the immanent criticism of the figure of conciliation in individual cases with the purpose of paying unpaid wages.

For this we use time as the master line for criticism. We go through procedural time, by the expectation of time and by the affects that involve time and social relations, such as fear, helplessness and hope.

We establish the role of the State in the exploitation of the labor force and the maintenance of capitalism, as well as the use of power and affection.

In addition, we present the time of the turnover and how conciliation and procedural delay can be useful for the capitalist gain.

We present conciliation as a tool for exploiting the working class as there is acceptance of conciliation based on the affections fear, hope and helplessness.

KEY WORDS: conciliation, time, exploration, pacification, state, process, surplus-value, fear, helplessness, hope, politics, precariousness 


\section{Sumário}

1 - INTRODUÇÃO 8

2 - DA CONCILIAÇÃO - INTRODUÇÃO 21

2.1 - CONCEITO, HISTÓRIA E CARACTERÍSTICAS DOS DISSÍDIOS INDIVIDUAIS NA JUSTIÇA DO TRABALHO__ 24

2.1.1 - CONCEITO DE CONCILIAÇÃO 24

2.1.2 - 2.1.2 - CARACTERÍSTICAS DOS DISSÍDIOS INDIVIDUAIS NA JUSTIÇA DO TRABALHO 30

2.2 - CONCILIAÇÃO, ESTADO E CAPITALISMO 37

3 - INTRODUÇÃO - TEMPO, MEDO E ESPERANÇA 42

3.1- O TEMPO E O PROCESSO 44

3.1.1 - O TEMPO HISTÓRICO 47

3.1.2 - O TEMPO NO PROCESSO TRABALHISTA 49

3.1.3 - O TEMPO E A ROTAÇÃO DO CAPITAL 55

3.2 - MEDO E DESAMPARO 58

3.3 - ESPERANÇA 66

4 - A CONCILIAÇÃO E O MAIS-VALOR 68

5 - CONCLUSÃO 72

6 - BIBLIOGRAFIA 78 


\section{1- INTRODUÇÃO}

"A luta de classes não é simples, como bem se presume; e ela é menos simples na medida em que tudo concorre para embaralhar as coisas; e, quando digo "tudo", refiro-me, é claro, à ideologia "dominante", com certeza não me refiro a uma "falsa consciência", a uma visão "invertida" que deveríamos colocar em pé, mas mais precisamente a um complexo de aparelhos (sindicatos, partidos, escola...), isso a que Althusser chamava, não faz muito tempo, de "aparelhos ideológicos de Estado"."1

““'Pour gouverner il faut avoir

Manteaux ou ruban em sautoir (bis)

Nous em tissons pour vous, grands de la terre,

Et nous, pauvres canuts, sans drap on nous enterre.

C'est nous les canuts

Nous sommes tout nus. (bis)

Mais notre règne arrivera

Quand votre règne finira.

Alors nous tisserons lê linceul du vieux monde

Car on entend dèjá la revolte qui gronde.

C'est nous les canuts

Nous n'irons plus nus." (canção dos tecelões de Lyon na época da Revolução Industrial) $)^{2}$

A tarefa de começar a redação de um trabalho, de uma pesquisa, do presente mestrado, parece tão complicada como a própria pesquisa. A angústia na escrita resta maior quando pela frente sabemos que o terreno não é amigável.

${ }^{1}$ BERNARD, Edelman. A legalização da classe operária. Coord. Tradução ORIONE, Marcus. $1^{\mathrm{a}}$ ed. São Paulo: Boitempo: 2016, páginas 18 e 19

2 "Para governar é preciso ter

Mantos ou condecorações em brasões

Nós os tecemos para vós, grandes da terra,

E nós, pobres operários, sem roupa, somos enterrados.

Somos nós os canuts (operários)

Nós estamos nus.

Porém, quando chegar nosso reino

Quando vosso reino terminar

Então nós teceremos a mortalha do velho mundo

Porque já se percebe a revolta que troa

Somos nós os canuts (operários)

Não estaremos mais nus." 
Amigável, aliás, não é palavra comum à construção do Direito do Trabalho, à construção do Direito Processual do Trabalho, mas parece ser a palavra chave para a ilusão da conciliação - "resolução amigável do litígio trabalhista". Ao longo do trabalho veremos que a ilusão de amigável, assim como outras ilusões vendidas como componente da conciliação pelo Poder Judiciário como representante do Estado, nada mais é que a luta estatal da pacificação à força das relações do proletariado com a burguesia e a busca pela exploração ao máximo da força de trabalho.

A proposta de tratar de um tema, como a conciliação, tão difundido e idealizado, sem suas difusões errôneas e sua idealização, nos traz a certeza que enfrentaremos resistência, ademais pela busca não de um revisionismo e sim da crítica.

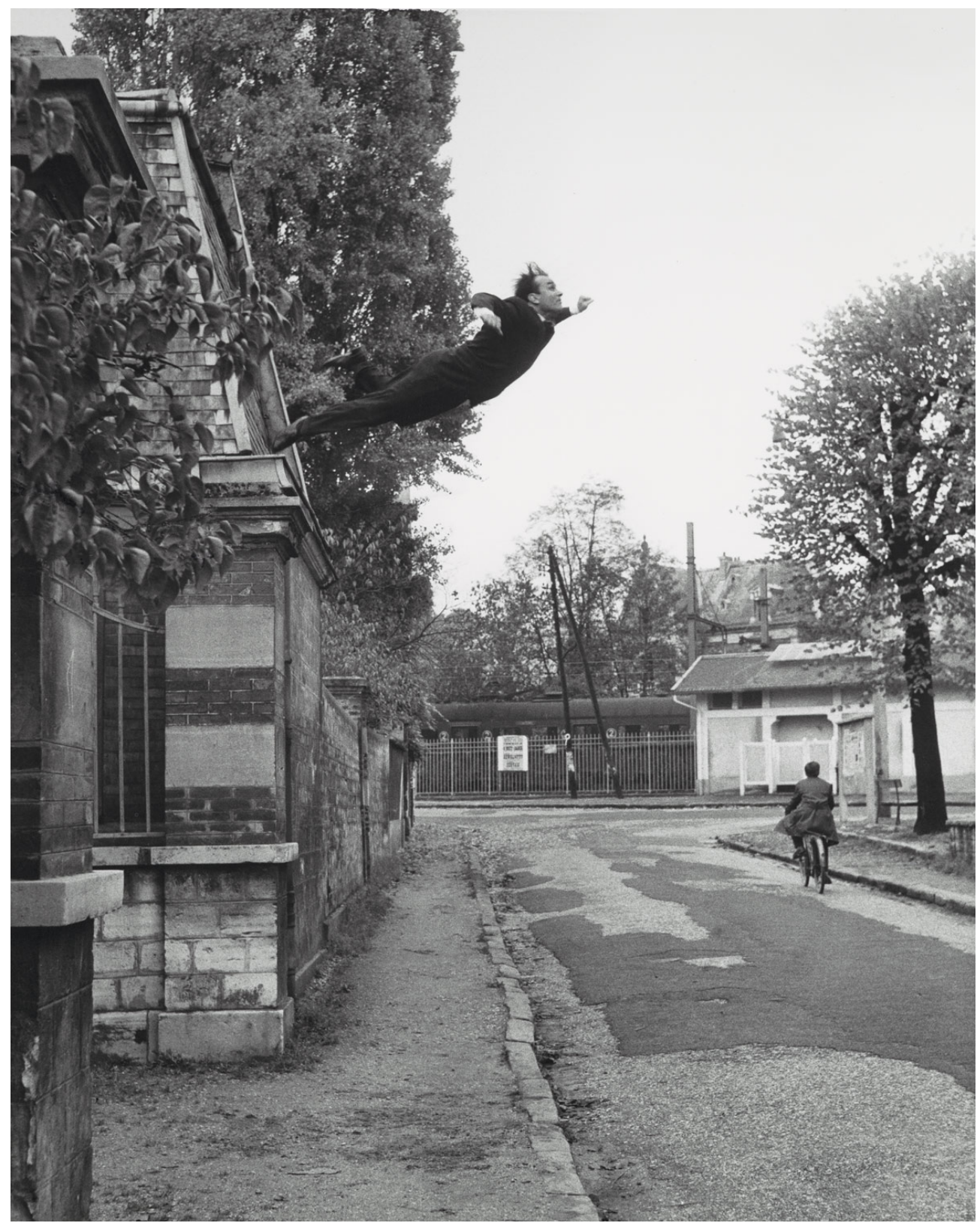


A figura de Yves Klein em Leap into the Void (Salto no vazio), trabalhada por Vladimir Safatle 3 , parece apropriada para o início da presente dissertação, não pela leitura do homem no salto ao vazio sem qualquer receio do chão, que para no instante como capaz de voar, de decolar como as ideias de Hegel, como uma foto para num tempo sem história, mas sim uma figura que salta ao vazio sem qualquer medo que o vôo, o além do ponto anterior da história, só pode ser conquistado de peito aberto ao concreto posto pela realidade, na espera que seu salto cause, além de feridas em seu corpo, algum estrago ao concreto que traça o limite do possível (e do impossível).

Klein persegue seu destino, o chão, ao subir em uma casa e se atirar à rua, ao asfalto, ao chão, mas por segundos desafia o impeditivo social que o proíbe voar (ou de acreditar que pode voar), desafia aquilo que está posto como certo e acabado.

De certo, a gravidade impedirá seu vôo, mas sua tentativa, mesmo com resultado certo, frustra o impeditivo da tentativa de voar, fere o dado como certo, fissura os limites representados pelo concreto do chão, mostra que podemos querer outros possíveis e impossíveis, apenas precisamos de nosso tempo, o tempo histórico.

O que nos interessa da ação de Klein é nossa leitura de subversão do dado, do tratado como certo, do propagado pelos aparelhos ideológicos como o possível. O salto no vazio rompe com a lógica de submissão.

Não nos importa olhar Klein como figura parada no tempo, como voador estático, e sim como aquele que transgride a lógica posta ao longo da história. Nos interessa uma crítica com processo histórico, com tempo histórico, e não o recorte sem tempo, sem história.

Como já é possível deduzir, o presente trabalho não trará qualquer conforto ao leitor, ao menos esta é a intenção, pois retira o véu do conforto, do dado, do assentado, do imutável, sobre as relações da Justiça, do Estado e do Direito com a exploração da força de trabalho das operárias e dos operários.

O retrato da conciliação, sem história, nos leva ao retrato da perfeição, do amigável, da solução pacífica, de fraternidade e igualdade; como narrado, vamos adicionar

3 SAFATLE, Vladimir. O circuito dos afetos: corpos políticos, desamparo e o fim do indivíduo. 2 ed. rev. Belo Horizonte: Autêntica Editora, 2016, página 34. 
o tempo histórico à conciliação judicial e colocá-la em confronto com a luta da classe operária, em confronto com as opressões operadas pela burguesia ao longo dos anos.

Tal crítica é necessária ao passo que a conciliação judicial ganha a cada ano importância e espaço na construção da figura da Justiça do Trabalho e com a busca de produtividade e resultados financeiros pelo Poder Judiciário Trabalhista tornou-se central para a jurisdição laboral e ferramenta de diminuição dos custos de produção para os empregadores, já que em um acordo pode-se reduzir o valor devido aos trabalhadores e, como diz o brocardo notório aos operadores de Direito, "melhor um acordo ruim que um bom litígio".

Devemos observar que a conciliação está assentada na Consolidação das Leis do Trabalho (Decreto-lei n. 5.425 de $1^{\circ}$ de maio de 1943) de maneira ampla. Como exemplos, temos as comissões de conciliação prévia (art. 625-A e seguintes da CLT) e a tentativa de conciliação das partes em audiência pelo magistrado (art. 846 e art. 850, ambos da CLT).

A importância do tema encontra-se na observação das ferramentas, institucionalizadas, de exploração do trabalhador e diminuição do preço da força de trabalho, sendo a conciliação uma dessas ferramentas.

A conciliação é "vendida" ao trabalhador como forma de resolução de conflitos justa, eficaz e célere, mesmo com políticas de instigação ao acordo ${ }^{4}$, como a Semana de Conciliação do Conselho Nacional de Justiça.

$\mathrm{Na}$ série histórica, de 2004 até 2014, foram homologadas 13.216.488 conciliações. Esse montante corresponde a $60,462 \%$ da média da população economicamente ocupada entre os anos de 2004 até 2014.

Ao ampliar conciliações a Justiça do Trabalho reflete o anseio da burguesia pela exploração do trabalho e manutenção da miséria para a classe trabalhadora. Esconde práticas como o sobretrabalho, o trabalho precário, entre outras formas de degradação do proletariado.

\footnotetext{
${ }^{4}$ No ano de 2012, no âmbito de Justiça do Trabalho, a Semana Nacional de Conciliação promoveu 13.570 acordos. Com a ampliação da política no ano de 2013 o número aumentou para 27.622 acordos. Fonte: Conselho Nacional de Justiça, estatísticas 2012 e 2013, disponíveis em http://www.cnj.jus.br/images/ programas/conciliacao/2012/relatório_final_Conciliacao2012.pdf e http://www.cnj.jus.br/images/programas/ conciliacao/2013/relatorio_conciliacao__2013.pdf
} 
Finalmente, cabe promovermos a crítica radical à conciliação, para desvelar o falso ambiente de pacificação trazido por esta figura e desvelar ao trabalhador o espaço de disputa entre o proletariado e a burguesia, para o trabalhador se engajar na luta contra a burguesia e contra o Estado que reproduz a lógica de exploração do capital.

Trata Marx no posfácio da segunda edição d'O Capital sobre seu método de investigação:

A investigação tem de se apropriar da matéria [Stoff] em seus detalhes, analisar suas diferentes formas de desenvolvimento e rastrear seu nexo interno. Somente depois de consumado tal trabalho é que se pode expor adequadamente o movimento real. Se isso é realizado com sucesso, e se a vida da matéria é agora refletida idealmente, o observador pode ter a impressão de se encontrar diante de uma construção a priori. Meu método dialético, em seus fundamentos, não é apenas diferente do método hegeliano, mas exatamente seu oposto. Para Hegel, o processo de pensamento, que ele, sob o nome de Ideia, chega mesmo a transformar num sujeito autônomo, é o demiurgo do processo efetivo, o qual constitui apenas a manifestação externa do primeiro. Para mim, ao contrário, o ideal não é mais do que o material, transposto e traduzido na cabeça do homem. ${ }^{5}$

Devemos partir do concreto posto para chegarmos à crítica do sistema que deságua no acordo de verbas salariais do proletário promovido pelo Judiciário Trabalhista.

Se fizéssemos a escolha por outro método provavelmente incorreríamos no estudo de algo sem qualquer correlação com a realidade, com o fático desfecho de reproduzir o mesmo, ou seja, poderíamos até construir outra ferramenta processual, diversa do acordo, contudo apenas reproduziria a exploração do trabalho e reafirmaria o sistema capitalista pois a crítica apenas seria feita na aparência e não na essência.

Portanto, devemos observar a conciliação na esfera do real (material). Só assim poderemos compreender como esta ferramenta processual pode ser utilizada de forma perversa contra o trabalhador e em prol da exploração do trabalho (manutenção do capitalismo).

${ }^{5}$ MARX, Karl. O Capital: crítica da economia politica: livro I: o processo de produção do capital. tradução: ENDERLE, Rubens. São Paulo: Boitempo, 2013, página 90. 
Causa espanto a busca de conciliação de maneira tão ampla ao passo que as ações, em sua grande maioria, tratam de verbas salariais não pagas, como demonstram os números do Conselho Nacional de Justiça:

Gráfico 3.53 - Assuntos mais demandados no Poder Judiciário.

1. DIREITO DO TRABALHO -Rescisão do Contrato de Trabalho/Verbas Rescisórias
2. DIREITO CIVIL - Obrigações/Espécies de Contratos
3. DIREITO DO CONSUMIDOR - Responsabilidade do Fornecedor/Indenização por Dano Moral
4. DIREITO TRIBUTÁRIO - Dívida Ativa
5. DIREITO CIVIL - Responsabilidade Civil/Indenização por Dano Moral
6. DIREITO CIVIL - Família/Alimentos
7. DIREITO CIVIL - Obrigações/Espécies de Títulos de Crédito
8. DIREITO PROCESSUAL CIVIL E DO TRABALHO - Liquidação / Cumprimento / Execução/Obrigação de Fazer / Não Fazer
9. DIREITO ADM. E OUTRAS MATÉRIAS DE DIREITO PÚBLICO - Organização Político - administrativa / Administração Pública/
10. DIREITO CIVIL - Obrigações/Inadimplemento
11. DIREITO DO TRABALtia por Tempo de Serviço
12. DIREITO DO TRABALHO - Remuneração, Verbas Indenizatórias e Benefícios/Salário / Diferença Salarial
13. DIREITO PROCESSUAL CIVIL E DO TRABALHO - Processo e Procedimento/Antecipação de Tutela / Tutela Específica
14. DIREITO DO TRABALHO - Rescisão do Contrato de Trabalho/Seguro Desemprego
15. DIREITO CIVIL - Responsabilidade Civil/Indenização por Dano Material
16. DIREITO CIVIL - Família/Casamento
17. DIREITO CIVIL - Coisas/Propriedade
18. DIREITO TRIBUTÁRIO - Impostos/IPTU/Imposto Predial e Territorial Urbano
19. DIREITO PROCESSUAL CIVIL E DO TRABALHO - Partes e Procuradores/Assistência Judiciária Gratuita
20. DIREITO PREVIDENCIÁRIO - Benefícios em Espécie/Auxílio-Doença Previdenciário

$5.281 .354(10,39 \%)$

$2.827 .291(5,56 \%)$

$2.039 .288(4,01 \%)$

$1.642 .997(3,23 \%)$

$1.258 .733(2,48 \%)$

$1.023 .112(2,01 \%)$

$842.560(1,66 \%)$

$784.756(1,54 \%)$

$761.444(1,50 \%)$

$714.364(1,41 \%)$

$700.595(1,38 \%)$

$687.621(1,35 \%)$

$687.508(1,35 \%)$

$673.809(1,33 \%)$

$658.534(1,30 \%)$

$635.194(1,25 \%)$

$626.812(1,23 \%)$

$615.289(1,21 \%)$

$609.494(1,20 \%)$

$605.328(1,19 \%) 6$

O Direito do Trabalho, mesmo com sua construção histórica de luta, não foi capaz de garantir por suas ferramentas as verbas salariais (com caráter alimentar) dos trabalhadores e trabalhadoras, e por conciliação judicial quer garantir o recebimento de valores menores que os devidos com base na demora do processo judicial e da cultura de pacificação dos conflitos, aqui conflito de classes.

A reforma na CLT promovida em 2017 demonstrou o desinteresse do Estado, na forma do Poder Legislativo, em garantir ferramentas de efetivação e proteção dos direitos dos trabalhadores e trabalhadoras, ao revés, ampliou a exploração e precarização através de forma legal, sem qualquer diálogo ou preocupação com a classe trabalhadora. Nesse sentido, temos:

Frente a um cenário de forte crise econômica e política, a reforma trabalhista é retomada na agenda nacional como parte das medidas liberalizantes e alicerçadas em

\footnotetext{
${ }^{6}$ Conselho Nacional da Justiça. Justiça em números 2015: ano-base 2014. Brasília: CNJ, 2015, página 50.
} 
um conjunto de outras reformas em implementação e tramitação tais como o congelamento do gasto público por 20 anos, a reforma da previdência, as privatizações, a redefinição do marco regulatório do Pré-sal, a venda de terras nacionais a estrangeiros, entre outras. Nessa perspectiva, um conjunto de medidas estruturais é adotado com o objetivo de criar um ambiente institucional favorável para o capital produtivo e para o rentismo, assegurando aos primeiros a possibilidade de reduzir custos por meio da reforma trabalhista e da ampliação da terceirização, e garantindo aos últimos a rentabilidade via redução dos gastos públicos e da reforma da previdência.

(...)

A estratégia de desmonte das políticas sociais e de retirada de direitos serve a dois propósitos: reduzir o tamanho do Estado na formulação e implementação de políticas públicas, reservando fatias cada vez maiores para a iniciativa privada em setores como saúde e educação, e possibilitar a privatização de empresas públicas como a Petrobras, entre outras. Com a diminuição do papel do Estado abre-se caminho para a redução da carga tributária, atendendo pleito antigo dos empresários, que pressionam por redução de impostos e pela reforma trabalhista.

O capitalismo contemporâneo, globalizado e hegemonizado pelos interesses das finanças, vem impactando regressivamente os direitos sociais e as instituições públicas (Belluzzo, 2013). O rebaixamento salarial que as formas precárias de contração promovem tem impacto direto nas receitas da seguridade social, ao mesmo tempo em que o suposto deficit nas contas da Previdência é usado como pretexto para justificar a urgência das reformas. A reforma trabalhista irá afetar de forma decisiva as fontes de financiamento da seguridade e criar imensas dificuldades para os trabalhadores conseguirem comprovar tempo de contribuição. ${ }^{7}$

De outra banda, o caráter alimentar das verbas conciliadas é importante para entendermos e criticarmos a dinâmica de pacificação da Justiça do Trabalho que não repara os direitos aos trabalhadores e tampouco garante a capacidade de alimento dos mesmos, ou seja, o Estado, ao pacificar, apenas reafirma a exploração e deixa os trabalhadores à mercê da fome, na subsistência.

Entender que o trabalhador deve converter o dinheiro recebido pelo seu trabalho em seus meios de subsistência é essencial para entendermos a perversidade do tempo processual e a mecânica de exploração da conciliação.

${ }^{7}$ UNIVERSIDADE ESTADUAL DE CAMPINAS - INSTITUTO DE ECONOMIA - GRUPO DE TRABALHO REFORMA TRABALHISTA. Contribuição Crítica à Reforma Trabalhista. Campinas, 2017, disponível em https://www.eco.unicamp.br/images/arquivos/ Dossie14set2017.pdf\&sa=U\&ved=0ahUKEwjmh9i0mqDYAhXDF5AKHWfcBBIQFggaMAE\&usg=AOvVa w3FwEEwhZk8JPyOc8Vj0vCs. 
O Direito do Trabalho não é capaz de responder: por que as demandas judiciais trabalhistas, em sua maioria, versam sobre a reparação de verbas salariais? A resposta passa pela incapacidade de resolvermos as necessidades dos trabalhadores, sua proteção, através das ferramentas e órgãos pensados para manutenção do capitalismo.

O direito do trabalho, no contexto posto, é regulador da força de trabalho e sua expressão em mercadoria.

A questão será trabalhada de maneira mais profunda em momento posterior da dissertação.

O produtivismo do Judiciário, através das conciliações e políticas institucionais para tal resolução dos conflitos laborais, encobre a precariedade, assim como a exploração, reafirmadas pelo Judiciário, das relações de trabalho, com a estrutural hipossuficiência dos trabalhadores e trabalhadoras em relação aos patrões que detêm o maquinário e o capital para a produção.

Vamos observar alguns números do Tribunal Superior do Trabalho e do Conselho Nacional de Justiça.

\begin{tabular}{|c|c|r|r|r|}
\hline Ano & $\begin{array}{c}\text { \% de } \\
\text { Conciliações no } \\
\text { ano }\end{array}$ & Processos novos & Processos Julgados & $\begin{array}{c}\text { Total de processos } \\
\text { conciliado em relação ao } \\
\text { processo julgados }\end{array}$ \\
\hline 2014 & 39,3 & 3.544 .839 & 3.396 .691 & 1.334 .899 \\
\hline 2013 & 40,5 & 3.479 .966 & 3.338 .921 & 1.352 .263 \\
\hline 2012 & 43,4 & 3.291 .189 & 3.194 .002 & 1.386 .196 \\
\hline 2011 & 43,3 & 3.069 .489 & 3.016 .219 & 1.306 .022 \\
\hline 2010 & 43,4 & 2.899 .647 & 2.878 .734 & 1.249 .370 \\
\hline 2009 & 42,8 & 2.988 .399 & 2.914 .547 & 1.247 .426 \\
\hline 2008 & 44,1 & 2.754 .283 & 2.730 .118 & 1.203 .982 \\
\hline 2007 & 43,9 & 2.650 .984 & 2.580 .396 & 1.132 .793 \\
\hline 2006 & 43,8 & 2.458 .941 & 2.368 .212 & 1.037 .276 \\
\hline 2005 & 44,3 & 2.410 .997 & 2.268 .279 & 1.004 .847 \\
\hline 2004 & 44,1 & 2.200 .070 & 2.180 .078 & 961.414 \\
\hline
\end{tabular}


O Tribunal Superior do Trabalho disponibilizou os valores pagos em conciliações na Justiça do Trabalho a partir do ano de 2013. Utilizaremos os dados de 2013 e 2014 para podermos comparar o número de conciliações e apreciar o valor médio pago aos trabalhadores e trabalhadoras em cada acordo:

\begin{tabular}{|c|c|c|r|r|}
\hline Ano & $\begin{array}{c}\text { Total de } \\
\text { processos com } \\
\text { conciliação } \\
\text { homologada }\end{array}$ & $\begin{array}{c}\text { Valores pagos em } \\
\text { conciliações na } \\
\text { Justiça do Trabalho }\end{array}$ & $\begin{array}{c}\text { Média de valor } \\
\text { pago por processo }\end{array}$ & $\begin{array}{c}\text { Média de valor em } \\
\text { salários mínimos }\end{array}$ \\
\hline 2014 & 1.334 .899 & $\mathrm{R} \$ 6.095 .298 .656,11$ & $\mathrm{R} \$ 4.566,12$ & 6,3 \\
\hline 2013 & 1.352 .263 & $\mathrm{R} \$ 9.874 .222 .902,92$ & $\mathrm{R} \$ 7.301,99$ & 10,76 \\
\hline
\end{tabular}

Ao analisarmos os dados não conseguimos, apenas com esses números, entender a busca pela confecção de conciliação entre as partes pela Justiça do Trabalho. A análise deve ser mais ampla, como já proposto, para entendermos a realidade da conciliação na Justiça do Trabalho, seus reais objetivos.

A leitura dos números da conciliação, total de resolução de processos, sem a inserção destes na realidade dos trabalhadores e trabalhadoras e sem observar a real relação do Estado com o modo de produção, nos levaria a leitura que a conciliação é modo de resolução de conflitos de forma pacífica e célere, que todos ganham, quando a realidade demonstra que os trabalhadores estão no jogo processual para perder, seja com a conciliação ou com a demora do processo trabalhista.

Acreditar na solução pacífica e igualitária é como enriquecer com o ouro dos tolos, pois a conciliação, o acordo, é outra forma de exploração dos trabalhadores e trabalhadoras e precarização das relações de trabalho.

Todo ano o Conselho Nacional de Justiça (CNJ) coordena a Semana Nacional da Conciliação. Durante uma semana, você tem a chance de conversar, negociar e chegar a um acordo justo e bom para todos, não importa de que lado você esteja. Afinal, quem concilia sempre sai ganhando!

(...)

\footnotetext{
8 Fonte: dados da Coordenadoria de Estatística e Pesquisa do Tribunal Superior do Trabalho, ano de 2015, disponível em http://www.tst.jus.br/conciliacoes1 e http://www.tst.jus.br/justica-do-trabalho2.
} 
Por que conciliar?

Todo cidadão pode procurar a Justiça para reivindicar seus direitos, caso se sinta lesado ou ameaçado. A cada dia, o Judiciário dispõe de acesso mais fácil para quem deseja ver sua reivindicação atendida com redução de tempo e custos.

A Conciliação é um meio de resolver uma demanda jurídica, pois representa a resolução de um conflito judicial de forma simplificada para ambas as partes. Por isso, a Conciliação está se consolidando como alternativa eficaz, rápida e satisfatória para solucionar diversas causas.

(...)

Rápida, barata, eficaz e... pacífica! ${ }^{9}$

Para o direito processual do trabalho a conciliação é uma maneira de solucionar o litígio laboral, como trata Carlos Henrique Bezerra Leite:

A conciliação é uma forma de solução de conflitos trabalhistas em que as próprias partes fazem concessões recíprocas acerca dos seus direitos subjetivos. O acordo, a transação e a renúncia podem ser objetos de conciliação, mas o Juiz do Trabalho pode recusar-se, validamente, a homologá-lo, desde que fundamente a sua decisão. O TST editou a Súmula n. 418 que considera inexistir direito líquido e certo à homologação de acordo celebrado pelas partes. ${ }^{10}$

Como podemos tratar a conciliação como composição igual entre as partes se a relação laboral é uma relação de desiguais?

Como o trabalhador e a trabalhadora que aplicaram sua força laboral em prol da produção e não receberam qualquer valor por isso, ou tiverem seus direitos diminuídos, podem negociar de forma igual com aquele que detém os meios de produção e o capital?

Como o trabalhador e a trabalhadora que aplicaram sua força laboral em prol da produção e não receberam qualquer valor por isso, ou tiveram seus direitos diminuídos, podem negociar de forma igual com aquele que detém os meios de produção e o capital?

Só têm igualdade formal, pois esta é viciada com a replicação da exploração da força de trabalho, ou seja, tratam como iguais todos como sujeitos de direitos com

\footnotetext{
${ }^{9}$ Fonte: Conselho Nacional de Justiça, sítio http://www.cnj.jus.br/programas-de-a-a-z/acesso-a-justica/ conciliacao.

${ }^{10}$ LEITE, Carlos Henrique Bezerra. Curso de direito processual do trabalho. 11 ${ }^{\mathrm{a}}$ ed. São Paulo: LTr, 2013, página 118.
} 
igualdade, pois precisam disto para validar o contrato de trabalho que determina, perante o direito e o Estado, as obrigações de trabalho.

Acreditar que a Justiça do Trabalho, o Estado, garantirá a igualdade na conciliação entre os trabalhadores e o empresariado é observar as resoluções destes, contudo acreditar que há igualdade entres esses personagens é um exercício de fé! Sim, um exercício de fé que tem como base a mística do Estado mediador de conflitos e garantidor do bem de todos, mas esse papel é interessado e desenhado no modo de produção e exploração capitalista.

O Direito é burguês, o direito do trabalho é burguês.

O Direito é burguês porque é instrumento do Estado burguês, capitalista.

Nos ensina Edelman que "Não existe o "direito do trabalho"; existe um direito burguês que se ajusta ao trabalho, ponto-final"11. O Direito do trabalho, com base na história do movimento operário, é o ajuste permanente na relação de exploração da força de trabalho no modo de produção capitalista, é o ajuste das relações entre capital e trabalho com a manutenção da exploração para geração do mais-valor.

Temos a certeza que o capitalismo só é possível por conta do Estado, este é garantidor da reprodução do modo de produção capitalista e sua dinâmica de reprodução social pulverizada pois as relações sociais são mais complexas, assim o Estado será o denominador comum para a reprodução capitalista.

De outra banda, por que as trabalhadoras e trabalhadores não se colocam contra a resolução do conflito trabalhista por acordo? Os trabalhadores conseguem entender a nova exploração do empregador através da conciliação?

Para rompermos a lógica de pacificação imposta pelo direito burguês, que no presente trabalho se materializa na conciliação sobre verbas salariais e gera mais-valor com a redução do preço pago pela força de trabalho aplicada, algo deve ser quebrado, rompido.

A quebra, a ruptura, talvez nos custe os ossos, o corpo, mas tem a capacidade de nos levar à visão, ao horizonte, de desarticulação do sistema de exploração, que a todo custo tenta se desvencilhar de seu maior problema, precisar de nosso corpo, de nossa forma de trabalho, para levar-nos à nossa própria exploração, assim o capitalista busca a obtenção

${ }^{11}$ BERNARD, Edelman. A legalização da classe operária. Coord. Tradução ORIONE, Marcus. $1^{\mathrm{a}}$ ed. São Paulo: Boitempo: 2016, página 19. 
do mais-valor com a menor quantidade de trabalho possível, contudo o trabalho, ainda, é indispensável à produção do mais-valor.

Pelo narrado, podemos concluir que a pesquisa feita no presente trabalho deve responder as seguintes questões:

1 - Na conciliação judicial há diminuição do valor pago pelo trabalho do reclamante, isto é, há o mais-valor em favor da empresa e operado ("validado") pelo Judiciário?

2 - Por que os trabalhadores e trabalhadoras se conformam com a exploração de sua força de trabalho que rege todas as relações, como no caso a conciliação na Justiça do Trabalho? 


\section{5 - CONCLUSÃO}

Vede um homem desses que andam perseguidos de pleitos, ou acusados de crimes, e olhai quantos o estão comendo. Come-o o Meirinho, come-o o Carcereiro, come-o o Escrivão, come-o o Solicitador, come-o o Advogado, comeo o Inquiridor, come-o a Testemunha, come-o o Julgador, e ainda não está sentenciado e já está comido. São piores os homens que os corvos. O triste que foi à forca, não o comem os corvos senão depois de executado e morto; e o que anda em juízo, ainda não está executado nem sentenciado, e já está comido. ${ }^{64}$

O tempo foi o carrasco no estudo apresentado, tanto da pesquisada quanto da classe trabalhadora. O tempo que parece inofensivo, que passa como um rio que trás novidades, pode ser ferramenta de opressão dos trabalhadores e trabalhadoras e reproduz a lógica de exploração capitalista.

Ao longo do trabalho buscamos responder aos seguintes questionamentos:

1 - Na conciliação judicial há diminuição do valor pago pelo trabalho do reclamante, isto é, há o mais-valor em favor da empresa e operado ("validado") pelo Judiciário?

2 - Por que os trabalhadores e trabalhadoras se conformam com a exploração de sua força de trabalho que rege todas as relações, como no caso a conciliação na Justiça do Trabalho?

Começaremos respondendo a segunda questão.

Os afetos sociais medo, esperança e amparo, fazem com que os cidadãos, em situação constante de desamparo pela exploração capitalista, idealizem o tempo. Portanto, o tempo real não será pleno ao passo que este sempre será uma versão imperfeita do tempo pretendido pelos trabalhadores e trabalhadoras.

Como o tempo material não satisfaz a ideia de tempo dos trabalhadores este pode ser utilizado pelos capitalista como ferramenta de exploração dos trabalhadores, em especial o tempo processual.

64 VIEIRA, Antônio. Sermão aos peixes. Pregado em São Luís do Maranhão em 1654. 
As pessoas idealizam que o tempo processual seria ótimo se fosse o tempo do pleito e da necessidade, isto é, pleiteado em juízo o direito deveria ser reparado de forma imediata, mas esta não é a realidade do tempo processual.

Por construção legislativa o tempo do processo é o tempo do percurso por todas as etapas processuais como pedido, defesa, produção de provas, sentença, recursos e execução. Tais etapas foram pensadas e negociadas entre os capitalistas e o governo, com a síntese da produção legislativa laboral.

A violação de direitos e o não cumprimento do tempo processual idealizado pelo litigante tocam o afeto medo dos litigantes. $\mathrm{O}$ medo do não resultado positivo, do não recebimento, da não Justiça.

De outra banda, a incerteza do por vir no processo judicial apresenta o desamparo, que tentar ser suprido, de forma enganosa como vimos no trabalho, pela atuação estatal, atuação do Poder Judiciário Trabalhista.

A esperança é ativada nos reclamantes ao passo que a conciliação é vendida como uma forma de resolução do conflito de maneira célere, próxima ao tempo idelizado pela parte. Contudo, com a esperança há a concretização do desamparo, pois para ter celeridade na solução do conflito os trabalhadores e trabalhadoras devem aceitar deixar parte de seus direitos, seus salários, para os capitalista.

Portanto, os a classe operária aceita a conciliação pelo medo, pelo desamparo e pela esperança.

De outra banda, se podemos construir uma crítica à aceitação da conciliação essa passa pelo Direito. O Direito não pode ser apenas a letra da Lei, se assim o for o Direito não vive e aqueles que do Direito dependem morrem pelas mãos daqueles que desejam que a interpretação e aplicação das leis seja restrita e fria.

No capitalismo é basilar tratar os indivíduos como sujeitos de direitos aptos (em igualdade) para a troca das mercadorias, sejam estas produtos ou a própria força de trabalho. A igualdade entre sujeitos de direito que permite a circulação mercantil só é possível dada a tutela do Estado sobre a propriedade privada, uma das bases do sistema capitalista, pois a afirmativa "só está apto a trocar aquele que é proprietário do bem" é calcada na realidade do capitalismo e dá base ao Direito capitalista. 
"a possibilidade de adotar um ponto de vista jurídico corresponde ao fato de que as diferentes relações na sociedade de produção mercantil se calcam sobre o tipo de relações de trocas comerciais e assumem, em consequência, a forma jurídica." 65

Podemos afirmar que o capitalismo só é possível por conta do Estado garantidor da reprodução do modo de produção capitalista e da sua dinâmica de reprodução social, assim o Estado será o denominador comum para a reprodução capitalista.

O Estado, em síntese, é forma política específica do domínio do capitalismo, necessário à reprodução capitalista ao passo que faz a intermediação universal das mercadorias e do trabalho através do aparato jurídico (instituições jurídicas) consolidadas no aparato estatal.

Não há qualquer neutralidade ou igualdade em tudo que é posto aos trabalhadores, o que há são igualdades formais que amparam o capitalismo, como a igualdade fabricada para o sujeito de direito que se assenta na possibilidade que todos os sujeitos se tornem proprietários e troquem seus bens, em apoio ao processo de circulação mercantil.

O processo que tem como base a igualdade e a Justiça, conceitos que ao observamos o processo de produção apenas se sustentam pela ideologia imposta aos sujeitos, demonstra a dualidade que se põe entre a aparência e a essência, ao passo que na aparência o processo judicial é ferramenta de resolução dos conflitos entre sujeitos e e de alguma forma promove a redistribuição de direito e promove o que é chamado de Justiça, contudo em sua essência o processo judicial não passa de ferramenta que busca reproduzir a lógica de exploração capitalista e apaziguar os ânimos de luta da classe trabalhadora no sujeito que demanda a reparação de seu direitos violados.

O embate travado no Judiciário sofre com as crises típicas do capitalismo, pois como é notório nos momentos de crise os capitalistas buscam a "solução" através da precarização dos trabalhadores e também pela superexploração da força de trabalho. Crises, como sabemos, são da essência do capitalismo, da acumulação de capitais típicas do modo de produção capitalista.

${ }^{65}$ PACHUKANIS, Evgeny Bronislavovich. op. cit. Página 51. 
“A desordem produz um fenômeno universal de despossessão e de intercâmbio. Mas tal despossessão universal não é apenas um fenômeno negativo, pois ele produz novas formas de interdependência e de simultaneidade. A burguesia abre o espaço para o advento de indivíduos histórico-universais caracterizados pela despossessão comum e pela simultaneidade de tempos até então completamente dispersos. Ela produz as condições para o advento de uma universalidade concreta que suspenderá e superará o estado de coisas atual. É assim que ela produz seus próprios coveiros." 66

Por figurar como terceiro na relação de exploração capitalista ao Estado é possibilitada, com aparente legimitidade, a repressão social e de constituição social, que decorre do medo social e do interesse na manutenção das forças produtivas e proteção da propriedade privada.

A conciliação em momentos de crise é uma das ferramentas utilizadas pelo Judiciário para apaziguar a luta de classes, ou seja, em momentos de desemprego, precarização das condições de trabalho é "melhor" ao trabalhador, na visão do capitalista e com base na ideologia imputada aos trabalhadores fazer um acordo e receber algum dinheiro para seu sustento e de seus familiares que aumentar o embate com sistema capitalista ou com os empresários.

A Justiça do Trabalho, como parte do que entendemos como Estado, é a reprodução/manutenção da lógica de exploração do trabalho e que o trabalhador demandante, dada a consciência de classe, deve combater a exploração proveniente do capitalista e do Estado.

A Justiça do Trabalho (Poder Judiciário) mantém o véu de legalidade, Justiça e promove a "paz social", isto é, apazigua a luta de classes ${ }^{67}$ através de ferramentas ideológicas. De forma idealista e interessada trata formalmente com paridade o trabalhador e empregador, mas através da análise concreta das relações sociais temos base para afirmar que a paridade entre ambos não existe e não existirá no regime capitalista, apenas há a igualdade formal, legal, que possibilita a circulação de mercadorias.

Não podemos negar o resultado prático individual de algumas ações, contudo dentro da lógica do capitalismo ao perder algumas ações ele reafirma o poder do Estado e a

\footnotetext{
${ }^{66}$ SAFATLE, Vladimir Pinheiro. op. cit.

67 “o Estado não processa o conflito social em termos de classe, mas, pelo contrário, maneja por excelência a célula do indivíduo-cidadão, a contradição de classe se resolve nos termos restritos das demandas individuais.” MASCARO, Alysson Leandro. Estado e forma política. São Paulo: Boitempo, 2013, página 49.
} 
capacidade de alienação dos trabalhadores e busca apaziguar a luta de classes, para melhor explorar o trabalho da classe operária.

Mas lembramos, perder o processo, após todo o trâmite processual, após a demora processual permitida pela legislação, possibilita ao capitalista promover a rotação do capital com ciclos menores de tempo.

De outra banda, o sujeito em Marx está inserido na lógica do proletariado. Já em Hegel o sujeito é observado em sua essência, em sua abstração, qual passamos a tratar através da doutrina do ser.

"Falar de ser, seria para Hegel sempre retornar aos domínios das identidades abstratas. Já a reconstrução hegeliana do conceito de essência seria, ao menos para Hegel, dotado da possibilidade de compreender os processos de temporalização.” 68

O ser, para Hegel, apenas é possível em sua essência, pois ao trata de ser apenas teríamos apenas as abstrações das identidades, ao revés da essência que comporta processos do tempo, ou seja, a essência encontra seu lugar no tempo, na história, faz a mediação entre o ser e o próprio conceito. Assim, o ser em sua essência é dado através dos fenômenos exteriores.

Assim, por a essência ser dada por elementos exteriores ela também é dada pela história, ou seja, o ser aceita a história em sua essência, como fator que o determina (se ousarmos falar que o ser tem determinações).

Nesse ponto o Direito não compreende a Filosofia, como trata Hegel o ser é maior que a própria definição do ser, é essência que se transparece no real pelo fenômenos, o Direito simplifica a figurado do que é sujeito como aquele que tem personalidade e é capaz de exercer seus direitos de forma autônoma ou assistida.

Portanto, se os entendimentos de Hegel e Marx sobre o que é o sujeito passam por uma ampliação do conceito restritivo e abarcar fatores externos ao próprio sujeito como o tempo, o processo judicial em que este sujeito está inserido necessariamente deve acompanhar os fatores externos que determinam o sujeito. Assim, quando falamos em luta

68 SAFATLE, Vladimir Pinheiro. Aula 2 - Dialética hegeliana, dialética marxista, dialética adorniana Curso Teoria das Ciências Humanas (Dialética hegeliana, dialética marxista, dialética negativa). Universidade de São Paulo: 2015. 
de classes, propriedade privada, espaço de disputa, devemos tomar em conta o tempo histórico e como esses fatores influenciam os sujeitos.

Se não levamos em consideração os aspectos externos apontados podemos incorrer na errônea reafirmação da exploração da classe trabalhadora calcada em verdades apenas formais, verdades na aparência, como no caso do positivismo qual aplica a letra da lei sem qualquer interpretação das determinantes sociais, sem considerar os cidadãos como sujeitos aos aparelhos ideológicos postos pela burguesia através do Estado.

Sobre a diminuição do valor pago aos trabalhadores e trabalhadoras, a resposta passa pelo tempo do processo, o tempo da produção e o preço pago na conciliação.

O tempo do processual é essencial ao capitalista para obter vantagem com a demanda judicial, ele consegue na conciliação pagar menos pelo trabalho executado e se não houver acordo judicial o tempo do processo garante que o tempo de rotação do capital será menor pois não será considerado no capital variável o pagamento de salário até a ordem judicial definitiva para pagamento.

Portanto, com a conciliação ou sem está o empregador inadimplente terá vantagem operada pelo tempo processual.

Com a conciliação o preço do trabalho já empregado na produção é renegociado, o firmado em contrato de trabalho é mitigado e há nova valoração do trabalho.

Portanto, com a diminuição do valor do trabalho necessário há aumento na taxa de mais-valor operado pela renegociação do preço da força de trabalho em conciliação no processo trabalhista quando a ação tem como objeto verbas salariais.

Os trabalhadores não precisam de resolução pacífica do processo laboral, eles precisam de seus salários ou dos meios para produzir aquilo que necessitam para sua vida (não apenas para seu sustento) pois detém a força de trabalho 


\section{6 - BIBLIOGRAFIA}

ADORNO, Theodor W. Três estudos sobre Hegel. Tradução. VACCARI, Ulisses Razzante. $1^{\text {a }}$ ed.. São Paulo: Editora Unesp, 2013.

ALARCÓN, Pietro Lora. Teoria geral do direito constitucional: a contribuição do marxismo. Revista Brasileira de Direito Constitucional. São Paulo, no 6, jul/dez, 2005, p. $553-570$.

ALEMÃO, Ivan. Conciliar é "legal"? : uma análise crítica da aplicação da conciliação na justiça do trabalho. Justiça do Trabalho, Porto Alegre, v.26, n.306, p.67-85, jun. 2009.

ALTHUSSER, Louis. Ideologia e aparelhos ideológicos do Estado. In: ZIZEK, Slavoj. Um mapa da ideologia. Rio de Janeiro: Contraponto.

ANTUNES, Ricardo. Adeus ao trabalho? 15a ed.. São Paulo: Cortez, 2011.

ARANTES, Paulo Eduardo. Hegel: a ordem do tempo. São Paulo: Hucitec/ POLIS, 2000. O novo tempo do mundo: e outros estudos sobre a era da emergência. $1^{\text {a }}$ ed.. São Paulo: Boitempo, 2014.

BATISTA, Flávio Roberto. Crítica da tecnologia dos direitos sociais. São Paulo: Outras Expressões; Dobra Editorial, 2013.

BECK, Ulrich. Un nuevo mundo feliz - la precariedad del trabajo en la era de la globalización. Barcelona: Paidós, 2000.

BERNARD, Edelman. A legalização da classe operária. Coord. Tradução ORIONE, Marcus. 1 ${ }^{\text {a }}$ ed. São Paulo: Boitempo: 2016,

BONAVIDES, Paulo. Do Estado Liberal ao Estado Social. $11^{\text {a }}$ e. São Paulo: Malheiros Editores Ltda, 2013.

BOMFIM, Benedito Calheiros. A outra face da conciliação judicial. $O$ Trabalho: doutrina em fascículos mensais. Brasília, n. 175, p. 6335-6336, set. 2011.

CESARINO JUNIOR, Antônio Ferreira. Direito social brasileiro - Volumes $1 e$ 2. $6^{a}$ ed. São Paulo: Saraiva Livreiros Editores, 1970.

CINTRA, Antônio Carlos de Araújo; GRINOVER, Ada Pellegrini; DINAMARCO, Cândido Rangel. Teoria geral do processo. $21^{\mathrm{a}}$ ed. São Paulo: Malheiros Editores Ltda, 2005. 
Conselho Nacional de Justiça. Justiça em Números 2011 - Justiça do Trabalho. Brasília, ano 2012.

CORREIA, Marcos Orione Gonçalves. A teoria da Constituição à luz da teoria da norma - um enfoque com destaque para as normas de Direitos Sociais. Revista Brasileira de Direito Constitucional, nº. 6, jul/dez, 2005, p. 281-303.

. Teoria geral do processo. $5^{\mathrm{a}}$ ed. São

Paulo: Saraiva, 2009.

Acesso à justiça e processo do trabalho.

in CORREIA, Marcus Orione Gonçalvez (organizadores). Curso de direito do trabalho direito processual do trabalho - Volume IV. São Paulo: LTr, 2007, p. 27-45.

COTRIM, Vera. Trabalho produtivo em Karl Marx - velhas e novas questões. São Paulo: Alameda, 2012.

CUNHA, Rodrigo Giostri da. O processo do trabalho como instrumento de efetivação dos direitos sociais trabalhistas - contribuições para o aprimoramento da prestação jurisdicional trabalhista. Dissertação de mestrado. São Paulo: Faculdade de Direito da Universidade de São Paulo, 2008.

DELLORE, Luiz. Teoria geral do processo contemporâneo. 2 ed. rev., atual. e ampl. São Paulo: Atlas, 2017

DUBUGRAS, Regina Maria Vasconcelos. A conciliação e a mediação na justiça do trabalho: conciliação qualificada. Revista do advogado, São Paulo, v. 34, n. 123, p. 115-122, ago. 2014.

ENGELS, Friedrich. A origem da família, da propriedade privada e do Estado. $9^{a}$ ed. tradução KONDER, Leandro. Rio de Janeiro: Editora Civilização Brasileira S.A., 1984.

ENGELS, Friedrich; KAUTSKY, Karl. O socialismo jurídico. tradução COTRIM, Lívia; NAVES, Márcio Bilharinho. 2ed. São Paulo: Boitempo, 2012.

FILGUEIRAS, Vitor Araújo. A justiça do trabalho e a conciliação impossível. Revista do Tribunal Regional do Trabalho da 15. Região, São Paulo, n. 45, p. 89-114, jul./ dez. 2014.

FREUD, Sigmund. Projeto de uma psicologia. Rio de Janeiro: Imago, 1995. O futuro de uma ilusão. In: Edição standard brasileira das obras psicológicas completas de Sigmund Freud, vol. XXI. Rio de Janeiro: Imago, 1990. 
GALVÃO, Andréia (org.). Marxismo, capitalismo, socialismo. São Paulo: Xamã; Campinas: UNICAMP, Instituto de Filosofia e Ciências Humanas, 2008.

GARCIA, Gustavo Filipe Barbosa. Curso de Direito Processual do Trabalho. $2^{\mathrm{a}}$ ed. Rio de Janeiro: Forense, 2013. . Novo código de processo civil: conciliação e mediação no processo do trabalho. Revista Síntese: trabalhista e previdenciária, São Paulo, v. 25, n. 305, p. 20-27, nov. 2014.

GOMES, Ângela de Castro (org.); SILVA, Fernando Teixeira da (org.). $A$ Justiça do Trabalho e sua história: os direitos dos trabalhadores no Brasil. Campinas: Editora da Unicamp, 2013.

HARVEY, David. Para entender O Capital - livro I. tradução ENDERLE, Rubens. São Paulo: Boitempo, 2013. - Para entender O Capital - livro II e III. tradução ENDERLE, Rubens. São Paulo: Boitempo, 2014. . Os limites do capital. tradução LOPES, Magda. São Paulo: Boitempo, 2013.

HEGEL, Georg Wilhelm Friedrich. Princípios da filosofia do direito. Tradução Orlando Vitorino. São Paulo: Martins Fontes, 1997. . Fenomenologia do espírito. tradução MENESES, Paulo. $9^{\mathrm{a}}$ ed.. Petrópolis, RJ: Vozes; Bragança Paulista: Editora Universitária São Franciso, 2014. HIRANO, Ana Farias. Acordos homologados pela Justiça do Trabalho: uma análise dos dissídios individuais na fase de conhecimento. Dissertação de mestrado. São Paulo: Faculdade de Direito da Universidade de São Paulo, 2009.

HOBSBAWN, Eric J. Os trabalhadores - estudos sobre a história do operariado. tradução MEDEIROS, Marina Leão Teixeira Viriato de. Rio de Janeiro: Paz e Terra, 1981. - Era dos extremos: o breve século XX: 1949-1991. tradução SANTARRITA, Marcos. 2a ed. São Paulo: Companhia das Letras, 1995.

KASHIURA JR, Celso Naoto. Sujeito de direito e capitalismo. $1^{\mathrm{a}}$ ed.. São Paulo: Outras Expressões; Dobra Universitária, 2014.

LEITE, Carlos Henrique Bezerra. Curso de Direito Processual do Trabalho. $11^{\mathrm{a}}$ ed. São Paulo: Ltr, 2013. 
LENIN, Vladimir Ilitch. O Estado e a revolução: o que ensina o marxismo sobre o Estado e o papel do proletariado na revolução. tradução: LOBO, Aristides. São Paulo: Expressão Popular, 2007.

LIPIETZ, Alain. As relações do capital - Trabalho no limiar do século XXI. Revista Ensaios FEE, Porto Alegre, n.12, 1991, p. 101-130.

LÖWY, Michael. Ideologias e ciência social: elementos para uma análise marxista. São Paulo: Cortez, 2008.

LUCHIARI, Valeria Ferioli Lagrasta. Mediação judicial: análise da realidade brasileira - origem e evolução até a Resolução n. 125, do Conselho Nacional de Justiça. Rio de Janeiro: Forense, 2012.

LUKÁCS, György. Lenin: um estudo sobre a unidade de seu pensamento. tradução ENDERLE, Rubens. São Paulo: Boitempo, 2012.

MAIOR, Jorge Luiz Souto; CORREIA, Marcus Orione Gonçalvez. O que é Direito Social ?. in CORREIA, Marcus Orione Gonçalvez (organização). Curso de direito do trabalho - teoria geral do direito do trabalho - Volume I. São Paulo: LTr, 2007, p. $13-40$.

MAIOR, Jorge Luiz Souto. Modernidade e Direito do Trabalho. Revista do Tribunal Superior do Trabalho. Brasília, v. 67, nº 1, jan/mar 2001, p. 153-159.

. Direito processual do trabalho: efetividade, acesso à justiça e procedimento oral. São Paulo: LTr, 1998.

. Curso de direito do trabalho: teoria geral do direito do trabalho, volume I, parte I. São Paulo: LTr, 2011.

- Curso de direito do trabalho: a relação de emprego, volume II. São Paulo: LTr, 2008.

.Relação de emprego e direito do trabalho: no contexto da ampliação da competência da justiça do trabalho. São Paulo: Ltr, 2007. .Revisão constitucional e direitos sociais. Revista do Tribunal Regional do Trabalho da 15a Região. Campinas, v. 29, p. 71-77, 2006.

MARX, Karl. O Capital: crítica da economia política: livro I: o processo de produção do capital. tradução: ENDERLE, Rubens. São Paulo: Boitempo, 2013. 
. O Capital: crítica da economia política: livro II:

o processo de circulação do capital. tradução: ENDERLE, Rubens. São Paulo: Boitempo, 2014.

. Crítica da filosofia do direito de Hegel. tradução:

ENDERLE, Rubens; DEUS, Leonardo de. São Paulo: Boitempo, 2005. . Grundrisse: manuscritos econômicos de

1857-1858: esboços da crítica da economia política. tradução DUAYER, Mario; SCHENEIDER, Nélio. São Paulo: Boitempo; 2011.

. Trabalho assalariado e capital \& salário, preço e lucro. $2^{\mathrm{a}}$ ed. São Paulo: Expressão Popular, 2010.

. O 18 de brumário de Luis Bonaparte. tradução SCHENEIDER, Nélio. São Paulo: Boitempo; 2011.

MASCARO, Alysson Leandro. Estado e forma política. São Paulo: Boitempo, 2013 Introdução ao estudo do direito. $4^{\mathrm{a}}$ ed.. São Paulo: Atlas, 2013. . Crítica da Legalidade e do Direito Brasileiro. $2^{\text {a }}$ ed. São Paulo: Quartier Latin, 2008.

MARANHÃO, Ney. Audiências de conciliação na execução trabalhista: considerações teóricas e proposições práticas. Revista Trabalhista: direito e processo, Rio de Janeiro, v. 11, n. 41, p. 38-49, mar. 2012. - Breves considerações sobre a notória transversalidade do paradigma conciliatório no âmbito do processo do trabalho. ADV Advocacia Dinâmica: seleções jurídicas, Rio de Janeiro, p. 30-34, maio, 2012.

MÉSZÁROS, István. Para além do capital: rumo a uma teoria da transição. 1ªed.. tradução CASTANHEIRA, Paulo Cezar; LESSA, Sérgio. São Paulo: Boitempo, 2011. . A montanha que devemos conquistar: reflexões acerca do Estado. $1^{a}$ ed.. tradução LAGOA, Maria Izabel. São Paulo: Boitempo, 2015. MORAES, Evaristo. Apontamentos de direito operário. $4^{\mathrm{a}}$ ed.. São Paulo: LTr, 1998. 
MORAES FILHO, Evaristo; FLORES DE MORAES, Antonio Carlos. Introdução ao estudo do direito do trabalho. $10^{\mathrm{a}}$ ed. São Paulo: Ltr, 2010.

MORAES FILHO, Evaristo. Direito do trabalho e a mudança social. A Cigarra. Rio de Janeiro, p. 33, maio de 1957. . O trabalho no mundo moderno. A Cigarra. Rio de Janeiro, p. 57, janeiro de 1955. . A massificação do homem. Revista Acadêmica.

Rio de Janeiro, novembro de 1940.

NAVES, Márcio Bilharinho. Marxismo e direito: um estudo sobre Pachukanis. São Paulo: Boitempo, 2008. . Marx - Ciência e revolução. São Paulo: Quartier Latin, 2008. . A questão do Direito em Marx. 1. ed. São Paulo: Outras Expressões; Dobra Universitário, 2014.

(Org.). O discreto charme do direito burguês: ensaios sobre Pachukanis. Campinas: UNICAMP, Instituto de Filosofia e Ciências Humanas, 2009.

(Org.). Análise marxista e sociedade em transição.

Campinas: UNICAMP, Instituto de Filosofia e Ciências Humanas, 2005.

NUNES, Luiz Antônio Rizatto. Manual da monografia jurídica. $5^{\text {a }}$ ed. São Paulo: Saraiva, 2007.

PACHUKANIS, Evgeny Bronislavovich. Teoria geral do Direito e marxismo. tradução CHAGAS, Sílvio Donizete. São Paulo: Editora Acadêmica, 1988.

PAULO NETTO, José. Introdução ao estudo do método de Marx. $1^{\text {a }}$ ed.. São Paulo: Expressão Popular, 2011.

POSTONE, Moishe. Tempo, trabalho e dominação social: uma reinterpretação da teoria crítica de Marx. São Paulo: Boitempo, 2014.

RATIER, Elthon Darvin Miranda. Indicadores para audiências de conciliação trabalhista: desempenho das partes para auxílio aos magistrados. Revista do Tribunal Regional do Trabalho da 24. Região, Campo Grande, n. 17, p. 29-39, 2012. 
RENAULT, Luiz Otávio Linhares; VIANA, Márcio Túlio. (Coord.). Comissões de conciliação prévia: quando o direito enfrenta a realidade: análises críticas em memória de Alaor Satuf Rezende. São Paulo: LTr, 2003. 332 p. TST 331.109.6 C733

SAFATLE, Vladimir. O circuito dos afetos: corpos politicos, desamparo e o fim do indivíduo. 2 ed. rev. Belo Horizonte: Autêntica Editora, 2016.

SCHIAVI, Mauro. Manual de Direito Processual do Trabalho. $1^{\mathrm{a}}$ ed. São Paulo: LTr, 2008.

. Princípios do processo do trabalho. $1^{\mathrm{a}}$ ed. São Paulo: Ltr,

2012.

. Novas reflexões sobre a renúncia, transação e conciliação no direito e no processo do trabalho à luz do novo CPC e da jurisprudência do TST. Revista LTr: legislação do trabalho, São Paulo, v.73, n.6, p.684-689, jun. 2009.

SILVA, Sayonara Grillo Coutinho Leornardo da. Duas notas sobre novas tutelas laborais no multifacetado desenho do mundo do trabalho contemporâneo. Revista do Tribunal Superior do Trabalho, Brasília, v. 74, nº 3, jul/set 2008, p. 121-148.

SILVA, Pedro Victor Vilas Boas da. Uma análise crítica da conciliação nos dissídios individuais do trabalho. Revista do Tribunal Superior do Trabalho, São Paulo, SP, v. 81 , n. 2 , p. 166-186, abr./jun. 2015.

STUTCHKA, Piotr. Direito de classe e revolução socialista. $3^{\mathrm{a}}$ ed.. tradução MÜNCHEN, Emil von. São Paulo: Editora Instituto José Luís e Rosa Sundermann, 2009

SUPIOT, Alain. Crítica del derecho del trabajo. Madrid: Ministério de Trabajo y Asuntos Sociales Subdirección General de Publicaciones, 1996.

TEODORO, Maria Cecília Máximo. Crise do Estado Social e o papel do juiz na efetivação de direitos trabalhistas. Dissertação de doutorado. São Paulo: Faculdade de Direito da Universidade de São Paulo, 2009.

VELloso, Carlos Mário da Silva. Dos Direitos Sociais na Constituição do Brasil. Palestra ministrada em "III Congresso Internacional da ANAMATRA - Associação Nacional dos Magistrados da Justiça do Trabalho - Ciclo de Estudos HispânicoBrasileiros", realizado nas cidades de Madri, Toledo e Barcelona, Espanha, no período de 10 a 18.03.2003. Disponível em: http://www.ufrnet.br/ tl/otherauthorsworks/dpr0027/ velloso_carlos_dos_direitos_sociais_na_cf.pdf. 
VIANNA, Márcio Túlio. Direito de resistência: possibilidades de autodefesa do empregado em face do empregador. São Paulo: LTr, 1996.

. Os paradoxos da conciliação. Revista LTr: legislação do trabalho, São Paulo, v. 78, n. 1, p. 7-16, jan. 2014.

ZANGRANDO, Carlos Henrique da Silva. Processo do Trabalho: processo de conhecimento, tomos I e II. São Paulo: LTr, 2009. 